\title{
Asbestosis, pleural plaques and diffuse pleural thickening: three distinct benign responses to asbestos exposure
}

\author{
P.A. Gevenois*\#, V. de Maertelaer+, A. Madani*, C. Winant*, G. Sergent*, P. De Vuyst**\#
}

Asbestosis, pleural plaques and diffuse pleural thickening: three distinct benign responses to asbestos exposure. P.A. Gevenois, V. de Maertelaer, A. Madani, C. Winant, G. Sergent, P. De Vuyst. CERS Journals Ltd 1998.

ABSTRACT: The aim of this study was to investigate by computed tomography (CT) whether asbestosis, diffuse pleural thickening and/or pleural plaques are statistically associated. We also tried to find criteria to differentiate between diffuse and circumscribed pleural thickening.

From 231 exposed workers, only those subjects whose radiograph showed neither bilateral calcified pleural plaques nor small pulmonary opacities higher than 1/1 grade according to the 1980 International Labour Office (ILO) Classification were considered. Scans were assessed for the presence of subpleural curvilinear lines, septal and intralobular lines, parenchymal bands, honeycombing, rounded atelectasis, pleural plaques and diffuse pleural thickening.

CT scans revealed pleural and/or lung abnormalities in 99 workers. Pleural plaques were unilateral in one-third of cases with plaques. Diffuse pleural thickening, parenchymal bands and rounded atelectasis were unilateral in, respectively, 62 and 69 and $75 \%$ of cases with the abnormality. Septal and intralobular lines, and honeycombing were always bilateral. CT signs could be grouped into three patterns: 1) septal and intralobular lines, and honeycombing corresponding to pulmonary fibrosis; 2) pleural plaques corresponding to parietal pleural fibrosis; and 3) diffuse pleural thickening, rounded atelectasis and parenchymal bands corresponding to visceral pleural fibrosis.

In these workers with a normal or near-normal radiograph, three groups of subjects with different responses were distinguished. Crow's feet and rounded atelectasis help to differentiate plaques from diffuse thickening.

Eur Respir J 1998; 11: 1021-1027.
*Dept of Radiology, Hôpital Erasme, Université Libre de Bruxelles, Brussels, Belgium. **Dept of Chest Medicine, Hôpital Erasme, Université Libre de Bruxelles, Brussels, Belgium. +Statistical Unit, IRIBHN, Université Libre de Bruxelles, Brussels, Belgium. \#Occupational Diseases Fund, Brussels, Belgium.

Correspondence: P.A. Gevenois

Dept of Radiology

Hôpital Erasme

Route de Lennik 808

1070 Brussels

Belgium

Fax: 3225554545

Keywords: Asbestos asbestosis

computed tomography pleural plaques

Received: June 161997

Accepted after revision February 51998
Asbestos-induced fibrosis can involve the pulmonary interstitium (asbestosis), the parietal pleura (pleural plaques) and/or the visceral pleura (diffuse pleural thickening) [1]. The histopathological feature of asbestosis consists of peribronchiolar and interstitial fibrosis, in which asbestos bodies appear on lung sections [1]. The high-resolution (HR) computed tomographic (CT) features of asbestosis have been extensively described. They include curvilinear subpleural lines, parenchymal bands, thickened interlobular (septal) and intralobular (core) lines, and later honeycombing $[2,3]$. These CT features are nonspecific, since they can also be observed in pulmonary fibrosis from other causes.

Pleural plaques are circumscribed and discrete areas of hyaline or calcified fibrosis, which are localized on the parietal pleura of the lateral chest wall, the diaphragm, or the mediastinum [1]. Involvement of the visceral pleura can be focal or diffuse [1]. When focal, the visceral changes appear on chest radiographs as small, pleuroparenchymal fibrous strands, known as "crow's feet". When extensive, pleural fibrosis is called "diffuse pleural thickening", usually accompanied by blunting of the costophrenic angles [4-7]. Rounded atelectasis (the folded lung), also called Blesovsky's syndrome, is thought to be a consequence of retractile visceral pleural fibrosis [8]. In contrast to pleural plaques, which are considered highly specific for asbestos exposure, especially when bilateral, diffuse pleural thickening is less specific since it can occur in a variety of conditions affecting the pleura, including connective tissue disease and drug exposure [9]. Diffuse pleural thickening is not precisely defined in radiological terms [5], and the 1980 International Labour Office (ILO) Classification did not distinguish between lesions located on the visceral from those on the parietal pleura. This is a potential source of confusion [10]. McLoud et al. [11] defined diffuse pleural thickening on chest radiographs as "a smooth, noninterrupted pleural density extending over at least onefourth of the chest wall" associated or not with costophrenic blunting. On CT scans, LYNCH et al. [12] defined diffuse pleural thickening as "a continuous sheet of pleural thickening more than $5 \mathrm{~cm}$ wide, more than $8 \mathrm{~cm}$ in craniocaudal extent, and more than $3 \mathrm{~mm}$ thick".

The aim of this study was to investigate, by CT scan, whether these different fibrotic lesions were actually statistically associated. We also tried to find more accurate criteria to distinguish between diffuse and circumscribed pleural thickening by CT scans, rather than by radiography. 


\section{Material and methods}

\section{Subjects}

Workers seeking compensation for pneumoconiosis were examined in the Belgian Occupational Diseases Fund by engineers, to confirm occupational exposure to dust, and by both an occupational and a chest physician for medical evaluation. These workers had their chest radiograph read by three experienced readers, according to the 1980 ILO Classification [10]. If the radiograph did not display obvious bilateral calcified pleural plaques, or small pulmonary opacities with a grade higher than $1 / 1$, and if the latency period (time from initial exposure) was at least $10 \mathrm{yrs}$, a CT scan of the chest was requested from the institution, to look for signs suggestive of asbestos-related disease. For the present study, the CT examinations requested by the Belgian Occupational Diseases Fund over a period of 4 yrs were considered. This group served as a referral. Individuals with known interstitial disease from other causes, previous thoracotomy or lung resection, and known malignancy were excluded, leaving 231 subjects (227 males and 4 females), ranging in age from 30-72 yrs (mean age \pm $\mathrm{SD}: 56 \pm 8 \mathrm{yrs}$ ) for the study. The duration of exposure to asbestos ranged from 1-48 yrs (mean \pm sD: $19 \pm 12$ yrs) and only 25 subjects were exposed for $<5$ yrs. One hundred and thirty one subjects were current smokers, and they had smoked $32 \pm 23$ pack-yrs (mean \pm SD). Thirty two subjects were exsmokers, and they had smoked $25 \pm 17$ pack-yrs. Sixty eight subjects were lifetime nonsmokers. Since the association between accelerated pleural changes and intake of ergoline drugs [9] was not well described at the time of this study, a systematic search of exposure to such drugs was not conducted.

\section{Computed tomography}

As previously recommended in asymptomatic asbestosexposed subjects, the CT examinations included conventional and HRCT scans [13]. These scans were obtained on a Siemens Somatom Plus (Siemens, Erlangen, Germany) scanner during breath-holding at full inspiration. The conventional scans were obtained from above the lung apices to below the posterior costophrenic angles at contiguous $1 \mathrm{~cm}$ intervals, using $10 \mathrm{~mm}$ collimation, $120 \mathrm{kV}$, $210 \mathrm{~mA}$, and a $1 \mathrm{~s}$ acquisition time. Images were reconstructed using a standard reconstruction algorithm and were photographed at two window settings, appropriate for viewing the lung parenchyma on the one hand, and the pleura and the mediastinum on the other. Contrast medium was not used.

The HRCT scans were performed immediately after the conventional CT scans and images were obtained from the lung apices to the posterior costophrenic angles, in supine and prone positions, at 20 or $30 \mathrm{~mm}$ intervals, depending on the height of the thorax, for a total of 18-24 images. All HRCT scans were acquired using $1 \mathrm{~mm}$ collimation, $137 \mathrm{kV}, 255 \mathrm{~mA}$, and a $1 \mathrm{~s}$ acquisition time. Images were reconstructed with an ultra-high-spatial frequency algorithm and photographed at window settings appropriate for the lung parenchyma.
Each CT examination was viewed simultaneously by two experienced chest radiologists. The findings from the CT scans were agreed upon by consensus between the two radiologists, who coded as present or absent on each side (left and right) the following pleural and parenchymal abnormalities, according to established criteria: 1) subpleural curvilinear lines, defined as linear densities within $1 \mathrm{~cm}$ of the pleura and parallel to the inner chest wall (fig. 1) $[2,3,14]$; 2) septal lines and intralobular (core) lines, defined as single or branching lines $1-2 \mathrm{~cm}$ in length, seen in the subpleural parenchyma (fig. 2) [2, 3]; 3) parenchymal bands, defined as linear densities $2-5 \mathrm{~cm}$ in length, extending through the lung to contact the pleural surface (fig. 3) [2, 3]; 4) honeycombing, defined as areas of lung containing small, cystic air spaces in the order of $0.3-1.0$ $\mathrm{cm}$ in diameter, with well-defined walls, which are often

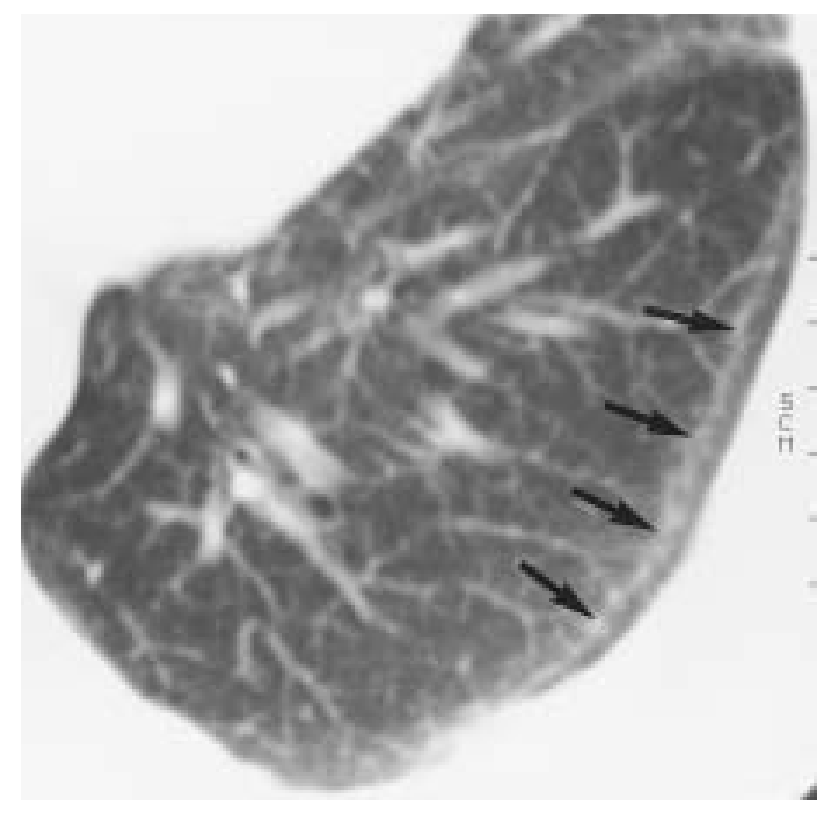

Fig. 1. - Subpleural curvilinear line. Linear area of increased density within $1 \mathrm{~cm}$ of the pleura and parallel to the inner chest wall (arrows).

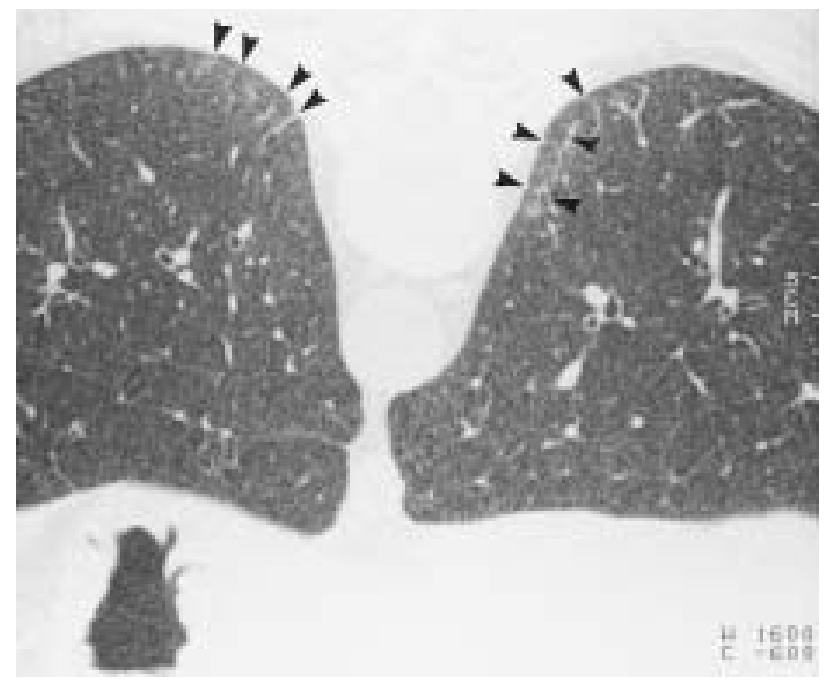

Fig. 2. - Septal lines and intralobular lines. Single or branching intralobular and interlobular lines up to $1-2 \mathrm{~cm}$ in length seen in the subpleural parenchyma (arrowheads). 


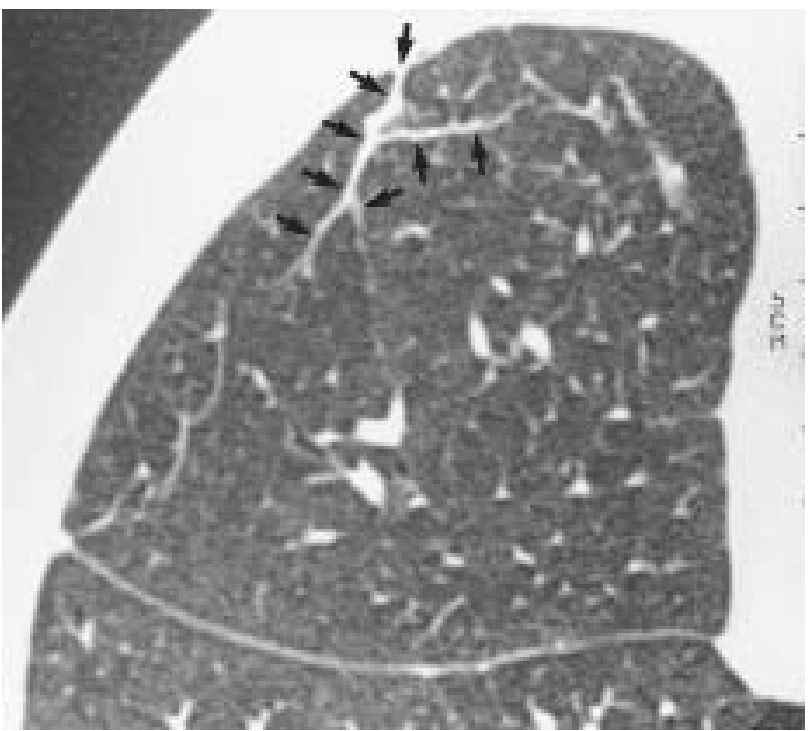

Fig. 3. - Parenchymal bands. Linear densities $2-5 \mathrm{~cm}$ in length, extending through the lung, extending to the pleural surface (arrows).

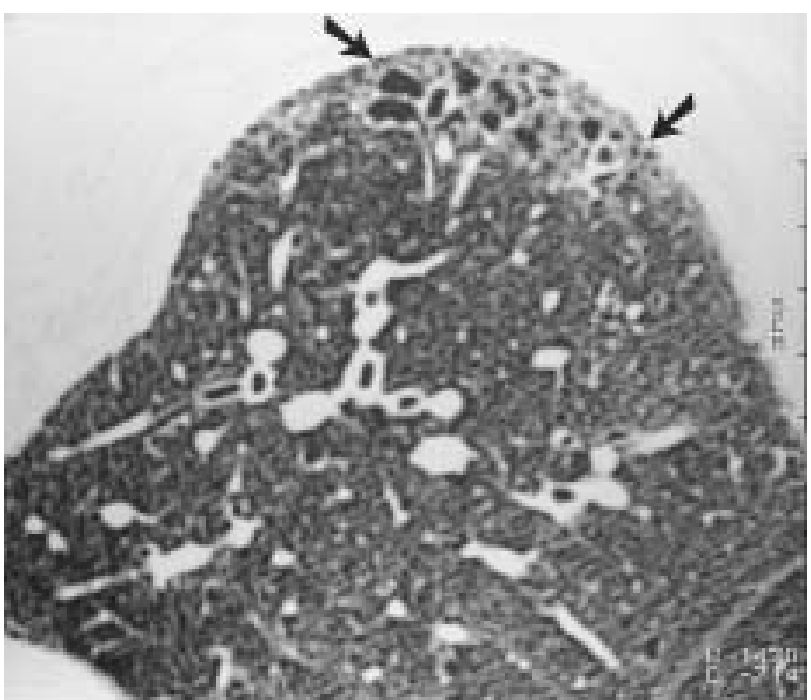

Fig. 4. - Honeycombing. Cystic air spaces on the order of $0.3-1.0 \mathrm{~cm}$ in diameter, with well-defined and often thick walls (arrows).

thick (fig. 4) [2, 3]; 5) rounded atelectasis, defined as a mass related to an area of pleural thickening associated with a partial interposition of lung between pleura and mass, and with a visible "comet tail" of vessels and bronchi sweeping into the lateral, or medial and lateral aspect of the mass (fig. 5) $[15,16]$; 6) pleural plaques, defined as discrete, dense, pleural linear structures, which may have a smooth or nodular inner surface (fig. 6); and 7) diffuse pleural thickening, defined as a contiguous sheet of pleural thickening more than $5 \mathrm{~cm}$ wide, more than $8 \mathrm{~cm}$ in craniocaudal extent and more than $3 \mathrm{~mm}$ thick (fig. 7) [12]. Increased densities seen only in the dependent areas of the lung were disregarded.

\section{Statistical analysis}

Some of the seven signs seemed more frequently bilateral, and others unilateral. In order to look for a statistic-


Fig. 5. - Rounded atelectasis. Mass (x) adjacent to a sheet of pleural thickening (arrowheads). Notice the backward displacement of the fissure (white arrow) reflecting the volume loss in the left lower lobe. In this particular case, a linear parenchymal band radiating from the mass into the surrounding lung parenchyma was associated (black arrow).

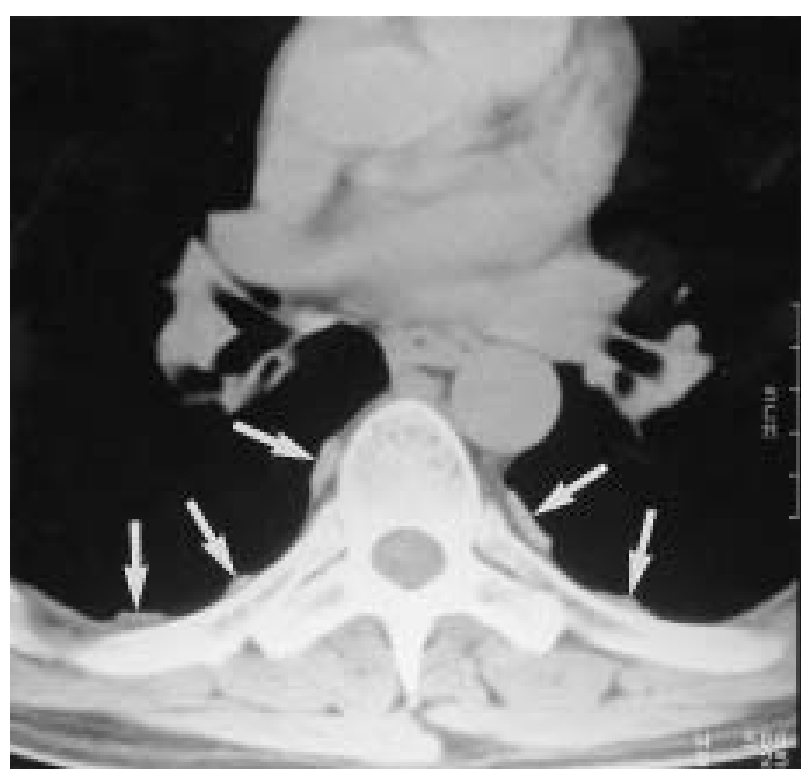

Fig. 6. - Pleural plaques. Discrete dense pleural linear structures (arrows).

ally significant difference between the probabilities that a sign appeared unilateral or bilateral, a binomial test was used, assuming that a sign has a 0.5 probability of being bilateral and a 0.5 probability of being unilateral. The subjects with no positive CT sign were omitted from these analyses. A statistically significant result indicates that the probability of appearing bilateral differs (i.e. is higher or lower) from the probability of appearing unilateral.

A second analysis was aimed at looking for possible associations between the signs. A sign was defined as positive if it was present on the left, on the right, or on both sides. A cluster analysis (i.e. a statistical procedure aimed at forming groups of similar objects) including the only subjects having at least one positive sign was performed. Cluster analysis is based on the concept of "distance" or 


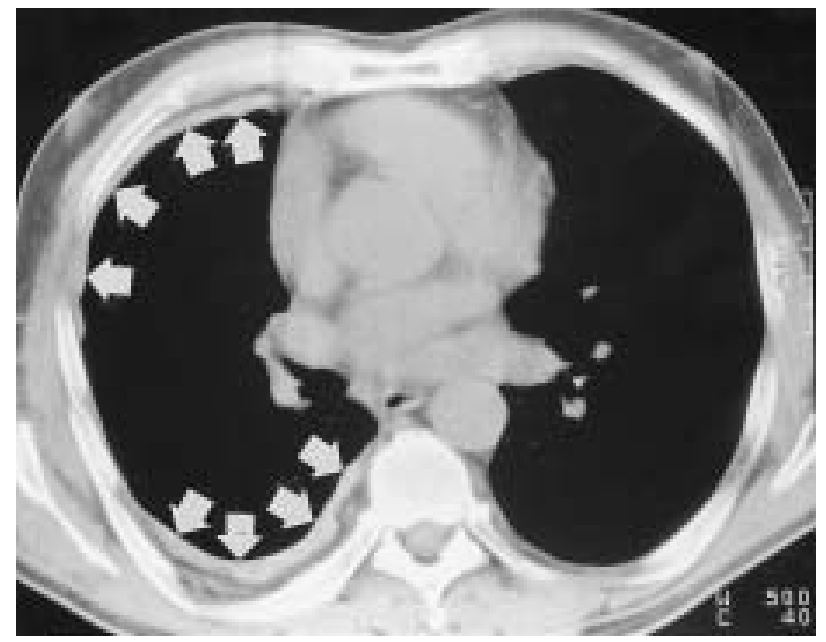

Fig. 7. - Diffuse pleural thickening. Sheet of pleural thickening, more than $5 \mathrm{~cm}$ wide and more than $3 \mathrm{~mm}$ thick (arrows). Contiguous scans show that the thickening is more than $8 \mathrm{~cm}$ in craniocaudal extent.

"dissimilarity measure"; it measures here how "far" apart two signs are (the less frequently two signs appear together, the "farther" apart they are). The dissimilarity measure of Lance and Williams (also known as the Bray-Curtis nonmetric coefficient) was chosen since it is appropriate for binary data and since it quantifies the "distance" between two signs without taking into account the number of subjects who are negative for both signs. Indeed, the number of subjects being negative for two signs is noninformative for detecting intersigns correlations. The dissimilarity measure between two signs $\mathrm{x}$ and $\mathrm{y}$ is defined by:

$$
\delta(x, y)=(b+c) /(2 a+b+c)
$$

where $\mathrm{a}$ is the number of subjects who are positive for $\mathrm{x}$ and $\mathrm{y}$, and $\mathrm{b}$ and $\mathrm{c}$ are the number of subjects positive for $\mathrm{x}$ or for y, respectively. Many methods are used for combining the signs into clusters. Among them, hierarchical agglomerative methods are the most frequently used [17]. More specifically, the average linking between groups method [18] was chosen since it uses information about all pairs of distance and not just the nearest or the farthest. It was decided that this process would be stopped as soon as three clusters were constituted.

The statistical software used was SPSS (Norusis MJ, SPSS for Windows, Professional Statistics, Release 5; SPSS Inc., Chicago, IL, USA, 1992).

\section{Results}

The CT scans detected no abnormality in $132(57 \%)$ of the 231 subjects. Thus, there were 99 subjects left for analysis. The frequency of each sign detected in these subjects is listed in table 1 . Pleural plaques were bilateral in $46(64 \%)$ and unilateral in $26(36 \%)$ cases. When unilateral, plaques had no predilection for any side. Septal and core lines, and honeycombing were bilateral in all cases. Diffuse pleural thickening, parenchymal bands and rounded atelectasis were unilateral in $20(62 \%), 24(69 \%)$, and 6 (75\%) cases, respectively. When unilateral, parenchymal bands and rounded atelectasis coincided with ipsilateral pleural thickening. Curvilinear subpleural lines were pre- sent in only one subject, and were not associated with any other sign. Therefore, such lines were not considered further for analysis.

Six radiographic signs were therefore submitted to cluster analysis. The procedure started out with six clusters, each one corresponding to one sign (fig. 8). At step 1, the signs "honeycombing" and "septal lines and intralobular lines" were combined into a single cluster since their distance was less than the distance between the clusters of any other pair. The second step merged "diffuse pleural thickening" and "parenchymal bands" into a second cluster, which was followed at the next step by adding "rounded atelectasis". At this third step, the three clusters appeared as: 1) septal lines and intralobular lines together with honeycombing; 2) diffuse pleural thickening together with parenchymal bands and rounded atelectasis; and 3) pleural plaques. The statistics of patients presenting the different CT patterns are listed in table 2.

Table 1. - CT findings compatible with asbestos-related disease detected in 99 subjects

\begin{tabular}{lccrc}
\hline CT scan & $\begin{array}{c}\text { Bila- } \\
\text { teral }\end{array}$ & $\begin{array}{c}\text { Unilateral } \\
\text { (right/left) }\end{array}$ & Total & $\mathrm{p}^{*}$ \\
\hline $\begin{array}{l}\text { Curvilinear } \\
\text { subpleural lines }\end{array}$ & 1 & 0 & 1 & - \\
$\begin{array}{l}\text { Septal and } \\
\text { intralobular lines }\end{array}$ & 11 & 0 & 11 & 0.001 \\
$\begin{array}{l}\text { Parenchymal bands } \\
\text { Honeycombing }\end{array}$ & 11 & $24(15 / 9)$ & 35 & 0.043 \\
$\begin{array}{l}\text { Rounded atelectasis } \\
\text { Pleural plaques }\end{array}$ & 6 & 0 & 6 & 0.031 \\
$\begin{array}{l}\text { Diffuse pleural } \\
\text { thickening }\end{array}$ & 46 & $6(3 / 3)$ & 8 & 0.289 \\
\hline
\end{tabular}

CT: computed tomography. *: p-value after binomial test.

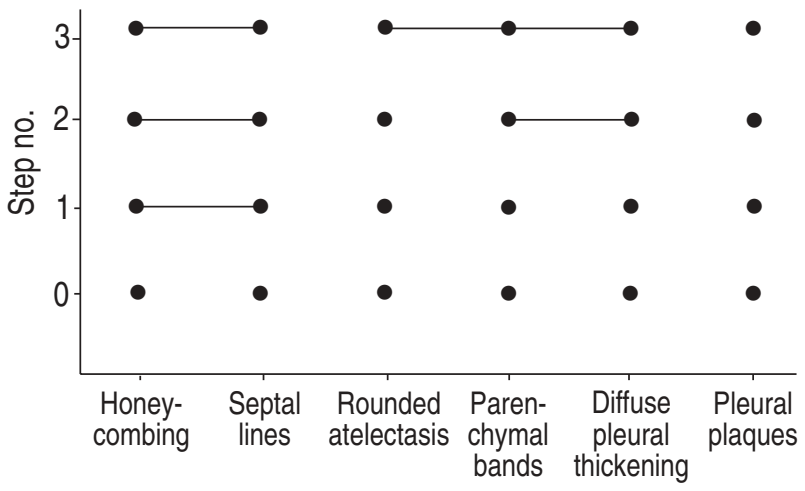

Fig. 8. - Graph illustrating the hierarchical associations of signs as resulting from the cluster analysis. These associations are represented by the connecting straight line.

Table 2. - Association into clusters of CT signs detected in 99 subjects

\begin{tabular}{lr}
\hline Computed tomography & $\mathrm{n}$ \\
\hline Septal and intralobular lines + honeycombing (1) & 7 \\
Diffuse pleural thickening + parenchymal bands + & 18 \\
$\quad$ rounded atelectasis (2) & \\
Pleural plaques (3) & 42 \\
$(1)+(2)$ & 2 \\
$(1)+(3)$ & 2 \\
$(2)+(3)$ & 27 \\
$(1)+(2)+(3)$ & 1 \\
\hline
\end{tabular}




\section{Discussion}

This study only included exposed subjects with normal chest radiographs or with low radiological grades (pulmonary opacities below 1/1), and allowed an analysis of the CT signs associated with asbestos exposure, namely their association in three clusters and their tendency to be unilateral or bilateral. Depending on the type of the lesion, several pathophysiological hypotheses can be put forward to explain the association of CT signs, differences in the sites of lesions (pleura versus lung) and the unilateral versus bilateral location.

\section{Association of CT signs in clusters}

The CT signs were not randomly associated and cluster analysis showed that there were three categories of CT signs, corresponding to different patterns of response to asbestos exposure. 1) Honeycombing, septal, and intralobular lines form one group, and suggest interstitial lung fibrosis. 2) Diffuse pleural thickening, parenchymal bands and rounded atelectasis form a second group, suggestive of diffuse fibrosis involving the visceral pleura. 3) Pleural plaques, without other signs, form the third group.

In HRCT studies of asbestos-related diseases, parenchymal bands have been considered as a sign of asbestosis $[2,3]$. The association of parenchymal bands and diffuse pleural thickening in the same cluster suggests that these bands reflect visceral pleural fibrosis rather than interstitial fibrosis.

Indeed, in other chronic infiltrative lung diseases with no primary visceral pleural involvement such as idiopathic pulmonary fibrosis and systemic sclerosis, these parenchymal bands are not reported at any stage. Thus, it appears that "crow's feet", pleural tags and parenchymal bands may correspond to similar lesions predominantly related to the fibrosis of the visceral pleura, and should be differentiated from HRCT features more suggestive of diffuse interstitial fibrosis, such as septal and intralobular lines, and honeycombing.

Parenchymal bands and rounded atelectasis, predominantly reflecting fibrosis of the visceral pleura, could enable the differentiation to be made between visceral pleural fibrosis and fibrosis strictly limited to the parietal pleura. Pleural plaques are covered by a normal mesothelium, and are not associated with adherence between the lung and the chest wall during respiratory movements, so that the lung can still slide along the chest wall and can fully expand [19]. In contrast, the involvement of the visceral pleura through adherence and/or retractile fibrosis is responsible for the shrinking, folding or incomplete inflation of the underlying lung parenchyma [20]. The presence of parenchymal bands and/or rounded atelectasis should be useful in differentiating pleural plaques from diffuse pleural thickening, when pleural thickening is too small to be considered as diffuse, according to dimensional criteria.

It seems, thus, that there are three categories of nonmalignant individual responses to asbestos inhalation: fibrosis of the lung parenchyma, fibrosis involving the visceral pleura (diffuse pleural thickening) and fibrosis of the parietal pleura (pleural plaques). We shall discuss several hypotheses that might explain individual differences in the predominant sites of lesions and why they could be independent of one another.

The pattern of response to asbestos fibre inhalation is determined by numerous and complex parameters, including fibre characteristics (type and size), cumulative dose, migration of fibres to the pleura (translocation), individual factors, and latency [20].

Asbestosis, diffuse pleural thickening and pleural plaques have different dose determinants [21]. Asbestosis is related to high cumulative exposures, probably in excess of 25 fibres $\cdot \mathrm{mL}^{-1} \cdot \mathrm{yr}^{-1}$. [22]. By contrast, pleural plaques are the most frequent response to asbestos exposure, appearing even with low-dose, often intermittent, exposures [21]. From a pathophysiological point of view, clearance mechanisms reduce the initial inhaled and deposited fibre burden in the deep lung: most of the fibres will be removed by the mucociliary clearance and a minority of them will migrate to the interstitium. An overload effect appears to be important in initiating the activation of lung in- flammatory cells leading to parenchymal fibrosis [23]. Having reached the interstitium, some of the fibres might then migrate to the pleura through lymphatics, and concentrate with other particles in certain areas of the parietal pleura, probably after a passage through the pleural space $[24,25]$. The lung plays the role of a filter, and it is conceivable that the total number of fibres reaching the pleura might be less influenced by the cumulative dose. This could explain why pleural plaques and mesothelioma can be associated with low-dose or intermittent exposures, which are insufficient to lead to asbestosis by an overload effect. Lung burden studies consistently recorded the heaviest burdens for asbestosis and lowest burdens for pleural plaques [21, 26, 27]. This difference is also reflected in the concentrations of asbestos bodies in the bronchoalveolar lavage fluid [28]. Diffuse pleural thickening and rounded atelectasis are reported to be associated with burden levels between those of plaques and those of asbestosis [29-33].

Concerning the type of fibres, several studies have demonstrated a much stronger correlation between the severity of lung fibrosis and the concentration of amphibole (amosite, crocidolite and tremolite) fibres, rather than chrysotile fibres [26, 27, 29].

Another potentially important factor relates to the translocation of fibres towards the pleura. The exact pathways followed by fibres to reach the pleura are poorly known $[24,34]$. The relative amount of inhaled fibres that reaches the pleura could differ between individuals, as in animal species [35]. Differences in translocation to the pleura have, for example, been put forward to explain the higher incidence of experimental pleural tumours induced in hamsters than in rats, after the inhalation of fibres [35].

It has also been shown that after intrapleural injection of asbestos, the development of pleural plaques, rather than diffuse pleural fibrosis, can be induced by changes in the inflammatory response. Comparing normal and nitrogen-mustard-treated (neutropenic) New Zealand White rabbits, SAHN and ANTONY [36] showed that after intraple-ural instillation of asbestos, the presence of large numbers of pleural macrophages led to pleural plaque formation, whereas a paucity of these mononuclear phagocytes resulted in diffuse pleural fibrosis without plaque formation.

Differences in latency should also be taken into consideration. Pleural plaques are rarely observed before $20 \mathrm{yrs}$ 
after the onset of exposure [37]. However, asbestos pleural effusion can occur as early as $1 \mathrm{yr}$ after the first exposure [37]. This could hypothetically explain why diffuse pleural thickening, as a sequela of pleural effusion, might appear before the detection of lung fibrosis or pleural plaques.

\section{Unilateral versus bilateral}

Septal and intralobular lines, and honeycombing, which reflects parenchymal fibrosis, were bilateral in all cases in this study. Previously radiographic and CT studies reported that unilateral pleural plaques were not infrequent [38, 39]. In contrast to these studies, we did not observe any side predominance, but it should be remembered that workers with bilateral calcified pleural plaques visible on the chest radiograph were not referred for CT scans and, therefore, a selection bias existed. As far as we know, the leftsided predominance for the presence as well as for the extent of asbestos-related pleural disease has been reported in radiographic studies $[39,40]$, but the only CT study reporting unilateral plaques did not investigate their side predominance [38]. In contrast to pleural plaques, diffuse pleural thickening, parenchymal bands and rounded atelectasis were bilateral in only a minority of the subjects included in the present study.

The most frequent unilateral lesion is diffuse pleural thickening, especially when associated with rounded atelectasis. Rounded atelectasis is a retraction and folding of the lung occurring in various pleural disorders associated with a retractile fibrosis of the visceral pleura secondary to pleural effusion [8, 41, 42]. Benign asbestos pleural effusion may be the initial event that results in visceral pleu-ral fibrosis and rounded atelectasis [4, 43]. This effusion is often asymptomatic and resolves spontaneously in the majority of patients [5]. When it leads to the fibrosis of the visceral pleura with subsequent diffuse pleural thickening, this fibrosis increases with each episode of recurrence $[4,5,43,44]$. Since benign asbestos pleural effusion is frequently unilateral, one may speculate that diffuse pleural thickening, rounded atelectasis and parenchymal bands, as possible sequelae of pleural effusion, predominate on one side. Benign asbestos pleural effusion can recur on the opposite side, but months to years may separate lesions appearing on one side from changes appearing on the other [45]. Again, since workers with obvious bilateral pleural abnormalities on the chest radiographs were not referred for CT scans, it is conceivable that the subjects included in the present study were in the time between two effusions.

In conclusion, this computed tomographic study demonstrated three distinct types of benign response to asbestos exposure: 1) parenchymal fibrosis, consisting of septal lines and intralobular lines, and honeycombing; 2) parietal pleural fibrosis, consisting of pleural plaques; and 3) visceral pleural fibrosis, consisting of diffuse pleural thickening, rounded atelectasis and parenchymal bands. This suggests that asbestos-induced lesions detectable by computed tomography will be located initially on one target organ only (lung parenchyma, parietal pleura or visceral pleura) rather than associated in one individual. This probably depends on differences in latencies, types of exposure and host responses. In practice, the absence of pleural signs should not be considered a clue against the diagnosis of asbestosis. It should be noted that this computed tomographic study deliberately excluded all subjects with chest radiograph opacity grades higher than $1 / 1$ in the parenchyma. A similar study including subjects with higher grades might not have revealed the observed clusters and the three types of response. It should also be emphasized that a pathological approach to heavily exposed workers might show a more frequent association of diseases [26, 27]. The statistical association of diffuse pleural thickening with rounded atelectasis, parenchymal bands and "crow's feet" should also lead to the presence of these lesions being taken into consideration in the differential diagnosis of diffuse versus circumscribed [10] pleural thickening. The distinction between parietal pleural plaques and diffuse pleural thickening can be important, since diffuse thickening is more likely to result in an impairment of lung function $[46,47]$.

\section{References}

1. Statement of the American Thoracic Society. The diagnosis of non malignant diseases related to asbestos. Am Rev Respir Dis 1986; 134: 363-368.

2. Aberle DR, Gamsu G, Ray CS, Feuerstein IM. Asbestosrelated pleural and parenchymal fibrosis: detection with high-resolution CT. Radiology 1988; 166: 729-734.

3. Aberle DR, Gamsu G, Ray CS. High-resolution CT of benign asbestos-related diseases: clinical and radiographic correlation. Am J Roentgenol 1988; 151: 883-891.

4. Hillerdal G. Non-malignant asbestos pleural disease. Thorax 1981; 36: 669-675.

5. Hillerdal G. Asbestos-related pleural disease. Semin Respir Med 1987; 9: 65-74.

6. Mackenzie FAF, Harries PG. Changing attitudes to the diagnosis of asbestos disease. J Roy Nav Med Serv 1970; 56: 116-123.

7. Hillerdal G, Malmberg P, Hemmingsson A. Asbestosrelated lesions of the pleura: parietal plaques compared to diffuse thickening studied with chest roentgenography, computed tomography, lung function, and gas exchange. Am J Indust Med 1990; 18: 627-639.

8. Cohen AM, Crass JR, Chung-Park M, Tomashefski JF. Rounded atelectasis and fibrotic pleural disease: the pathologic continuum. J Thorac Imag 1993; 8: 309-312.

9. Pfitzenmeyer P, Foucher P, Dennewald G, et al. Pleuropulmonary changes induced by ergoline drugs. Eur Respir J 1996; 9: 1013-1019.

10. International Labour Office. Guidelines for the used of ILO International Classification of radiographs of pneumoconioses. Rev. Edn. International Labour Office safety and health series no. 22 (Rev 80). Geneva, International Labour Office, 1980.

11. McLoud TC, Woods BO, Carrington CB, Epler GR, Gaensler EA. Diffuse pleural thickening in an asbestosexposed population: prevalence and causes. Am J Roentgenol 1985; 144: 9-18.

12. Lynch DA, Gamsu G, Aberle DR. Conventional and high resolution computed tomography in the diagnosis of asbestos-related diseases. Radiographics 1989; 9: 523551.

13. Gevenois PA, De Vuyst P, Dedeire S, Cosaert J, Vande Weyer R, Struyven J. Conventional and high-resolution $\mathrm{CT}$ in asymptomatic asbestos-exposed workers. Acta Radiol (Diagn) 1994; 35: 226-229. 
14. Yoshimura H, Hatakeyama M, Otsuji H, et al. Pulmonary asbestosis: CT study of subpleural curvilinear shadow. Radiology 1986; 58: 653-658.

15. Lynch DA, Gamsu G, Ray CS, Aberle DR. Asbestosrelated focal lung masses: manifestations on conventional and high-resolution CT scans. Radiology 1988; 169: 603607.

16. Doyle TC, Lawler GA. CT features of rounded atelectasis of the lung. Am J Roentgenol 1984; 143: 225-228.

17. Aldenderfer MS, Blashfield RK. Cluster Analysis. Beverly Hills, Sage, 1984.

18. Sokal R, Michener CD. A statistical method for evaluating systematic relationships. Univ Kansas Sci Bull 1958; 38: 1409-1438.

19. Light RW. Pleural Diseases. Baltimore, MD, Williams and Wilkins, 1995; pp. 299-310.

20. Browne K. Asbestos-related disorders. In: Parkes WR, ed. Occupational Lung Disorders. Oxford, ButterworthHeinemann, 1994; pp. 411-504.

21. Becklake M, Case B. Fiber burden and asbestos-related lung disease: determinants of dose-response relationships. Am J Respir Crit Care Med 1994; 150: 1488-1492.

22. Peto J, Doll R, Hermon C, Binns W, Clayton R, Goffe T. Relationship of mortality to measures of environmental asbestos pollution in an asbestos textile factory. Ann Occup Hyg 1985; 29: 305-355.

23. Oberdörster G. Lung particle overload: implications for occupational exposures to particles. Regul Toxicol Pharmacol 1995; 27: 123-135.

24. Boutin C, Dumortier P, Rey F, Viallat JR, De Vuyst P. Black spots concentrate oncogenic asbestos fibers in the parietal pleura. Am J Respir Crit Care Med 1996; 153: 444-449.

25. Rey F, Viallat JR, Farisse P, Boutin C. Pleural migration of asbestos fibers after intratracheal injection in rats. Eur Respir Rev 1993; 3: 145-147.

26. Churg A, Vedal S. Fiber burden and patterns of asbestosrelated disease in workers with heavy mixed amosite and chrysotile exposure. Am J Respir Crit Care Med 1994; 150: 663-669.

27. Churg A, Wright JL, Vedal S. Fiber burden and patterns of asbestos-related disease in chrysotile miners and millers. Am Rev Respir Dis 1993; 148: 25-31.

28. De Vuyst P, Dumortier P, Moulin E, Yourassowsky N, Yernault JC. Diagnostic value of asbestos bodies in bronchoalveolar lavage fluid. Am Rev Respir Dis 1987; 136: 1219-1224.

29. Gibbs AR, Pooley FD. Analysis and interpretation of inorganic mineral particles in "lung" tissues. Thorax 1996; 51: 327-334.

30. Voisin C, Fisekci F, Voisin-Saltiel S, Ameille J, Brochard P, Pairon JC. Asbestos-related rounded atelectasis. Radiologic and mineralogic data in 23 cases. Chest 1995; 107: $477-481$.

31. Rudd RM. New developments in asbestos-related pleural disease. Thorax 1996; 51: 210-216.

32. Gibbs AR, Stephens M, Griffiths DM, Blight BJN, Pooley FD. Fibre distribution in the lungs and pleura of subjects with asbestos related diffuse pleural fibrosis. $\mathrm{Br} J$ Indust Med 1991; 48: 762-770.

33. Wagner JC, Moncrieff CB, Coles R, Griffiths DM, Munday DE. Correlation between fibre content of the lungs and disease in naval dockyard workers. Br J Indust Med 1986; 43: 391-395.

34. Craighead JE, Mossman BT. The pathogenesis of asbestos-associated diseases. N Engl J Med 1982; 306: 14461455.

35. Achard-Ellouk S, Jaurand MC. Review on animal/in vitro data on biological effects of man made fibers. Environ Health Persp 1994; 102: Suppl. 2, 47-61.

36. Sahn SA, Antony VB. Pathogenesis of pleural plaques. Relationship of early cellular response and pathology. Am Rev Respir Dis 1984; 130: 884-887.

37. Epler GR, Gaensler EA. Prevalence of asbestos pleural effusion in a working population. JAMA 1982; 247: 617622.

38. Neri S, Antonelli A, Falaschi F, Boraschi P, Baschieri L Findings from high resolution computed tomography of the lung and pleura of symptom free workers exposed to amosite who had normal chest radiographs and pulmonary function tests. Occup Environ Med 1994; 51: 239 243.

39. Withers BF, Ducatman AM, Yang WN. Roentgenographic evidence for predominant left-sided location of unilateral pleural plaques. Chest 1984; 95: 1262-1264.

40. Hu H, Beckett L, Kelsey K, Christiani D. The left-sided predominance of asbestos-related pleural disease. Am Rev Respir Dis 1993; 148: 981-984.

41. Mintzer RA, Gore RM, Vogelzang RL, Siegfried H. Rounded atelectasis and its association with asbestosinduced pleural disease. Radiology 1981; 139: 567-570.

42. Hanke R, Kretzschmar R. Round atelectasis. Semin Roentgenol 1990; 25: 174-182.

43. Eisenstadt HB. Pleural effusion in asbestosis. $N$ Engl $J$ Med 1974; 190: 1025.

44. Lilis R, Lerman Y, Sekiloff IJ. Symptomatic benign pleural effusions among asbestos insulation workers: residual radiographic abnormalities. Br J Indust Med 1988; 45: 443-449.

45. Hillerdal G, Ozesmi M. Benign asbestos pleural effusion: 73 exsudates in 60 patients. Eur J Respir Dis 1987; 71: 113-121.

46. Yates DH, Browne K, Stidolph PN, Neville E. Asbestosrelated bilateral diffuse thickening: natural history of radiographic and lung function abnormalities. Am J Respir Crit Care Med 1996; 153: 301-306.

47. Schwartz DA, Galvin JR, Yagla SJ, Speakman SB, Merchant JA, Hunninghake GW. Restrictive lung function and asbestos-induced pleural fibrosis. A quantitative approach. J Clin Invest 1993; 91: 2685-2692. 